\title{
Screening for Psychopathology in the Clinical Practice
}

\author{
Anne Eland-Goossensen, PhC, ${ }^{*}$ Ien van de Goor, PhD, ${ }^{*}$ \\ Henk Garretsen, PhD, ${ }^{*}$ and Joost Schudel, MD, PhD $\dagger$ \\ *Institute for Addiction Research Rotterdam (IVO), Heemraadssingel lgu, 3021 DM Rotterdam, The Netherlands; \\ $\dagger$ Department of Psychiatry, University Hospital Rotterdam, Dr. Molewaterplein 40, 3015 GD Rotterdam, The Netherlands
}

\begin{abstract}
Different instruments are used in clinical practice to assess comorbid psychopathology in addicted individuals. This study is aimed at comparing two of those instruments. In total, 327 heroin-and methadone-addicted individuals were interviewed in three treatment settings and outside treatment. Instruments used are the Addiction Severity Index (ASI) and the Composite International Diagnostic Interview (CIDI). The former instrument results in a general measure of severity of psychopathology, while the latter results in categorical DSM-III-R diagnoses. A comparison of the results show, however, that the two types of data do not agree to a large extent. By using the DSM-III-R data as golden standard, it appeared that a part of the psychopathology cases was missed out by the ASI severity measures. The results, that are especially of interest for clinicians using the ASI, are presented for various disorders. 1997 Elsevier Science Inc.
\end{abstract}

Keywords-addiction; heroin; psychopathology; psychiatric interview; assessment.

\section{INTRODUCTION}

COMORBID OPIATE ADDICTION and psychopathology have been the central themes in several recent scientific publications. Some authors described prevalences of the so-called 'dual diagnosis' problems (Abbot, Weller, \& Walker, 1994; Darke, Wodak, Hall, Heather, \& Ward, 1992; Hendriks, 1990; Raskin \& Miller, 1993; Regier et al., 1990; Rounsaville, Weissman, Kleber, \& Wilber, 1982; Swift, Williams, Neill \& Grenyer, 1990). Others discussed the causality of these problems (Lehman, My-

\footnotetext{
This study could be realized because of grants by the Nationaal Fonds voor de Geestelijke Volksgezondheid, the Municipality of The Hague and the Trustfonds of the Erasmus University. The authors wish to thank the respondents, Liesbeth Vollemans for her valuable help during the fieldwork and the participating treatment settings, Vcrslavingscircuit Bloemendaal and Centrum Verslavingzorg Zeestraat.

Requests for reprints should be addressed to Anne Eland-Goossensen, Institute for Addiction Research Rotterdam, Heemraadssingel Igu, 3021 DM Rotterdam, The Netherlands. E-mail: eland@ivo.fgg.eur.nl
}

ers, \& Corty, 1989; Lehman, Myers, Thompson, \& Corty 1993; Turnbull \& Roszell, 1993). Hypotheses, such as the possibility that different drug use patterns result in different types of psychopathology, were investigated also (Regier et al., 1990). In these publications, the psychopathology has been assessed with various instruments. One of these is the Addiction Severity Index (Hendriks, Kaplan, Limbeck, \& Geerlings, 1989; McLellan, Luborsky, Woody, \& O'Brien, 1980), which is used with increasing frequency in treatment programs, scientific studies, and for registration purposes. An important advantage of the ASI is the multidimensional concept of addiction problems. This makes it possible to study problems in different aspects of life, including psychiatric problems within one instrument. As for addicted individuals with psychiatric comorbidity, for instance, the ASI is capable of describing the nature and extent of drug problems as well as psychiatric problems (McLellan et al., 1983; Rounsaville, Kosten, Weissman, \& Kleber, 1986; Stoffelmayer, Benishek, Humphreys, Lee, \& Mavis, 1989). Although the ASI was never meant for screening 
on psychopathology, it has been used as such in practice by clinicians and researchers.

However, given the complex nature of the comorbid psychiatric and addiction problems (Lehman, Myers, Dixon, \& Johnson, 1994), there is a disadvantage to the ASI. The psychiatry section results in a dimensional measure, expressing severity that is not specific enough to describe the psychiatric problems in terms of a classification system, such as for instance categorical $D S M$ $I I I-R$ disorders. Instruments that provide a better distinction between symptom level and disorder level on the one hand contribute to an improved insight in the problem complexity by describing types of psychopathology. But, on the other hand, they require considerably more interview time, which is often lacking in treatment settings and research situations. Information about the relation between the ASI psychiatry section and specific psychiatric disorders may be useful for those clinicians who are not able to conduct an elaborate psychiatric interview. Therefore, the aim of this paper is to describe to what extent the psychiatry section of the ASI reflects $D S M-I I I-R$ disorders, assessed with the Composite International Diagnostic Interview (Robins et al., 1989). An earlier study of Hendriks (1990) showed that, compared with the psychiatric symptom check list SCL-90 (Derogatis, 1983) and the Beck Depression Inventory (Beck, Ward, Mendelson, Mock, \& Erbaugh, 1961) the ASI was the best screening instrument for anxiety-related disorders and depressive disorders. Among opiate-addicted individuals who participated in a residential detoxification program, $81 \%$ of the psychopathology cases could be identified with a severity rating of 5 or higher in the psychiatry section of the ASI. In this instance, $55 \%$ of the cases without psychopathology were correctly identified.

\section{MATERIALS AND METHODS}

\section{Subjects}

The central topic of this publication is part of a larger study in which opiate-addicted individuals in and outside of treatment are compared. During a period of about 30 months in which data were gathered, 327 opiate-addicted individuals were interviewed. The respondents had been dependent on opiates for at least the past 2 years, which is in accordance with $D S M-I I I-R$ criteria, and they were 18 years or older. Respondents who stayed in the treatment setting for less than 2 weeks were excluded from the study. Subjects were acquired in four settings. In a low-threshold methadone program, 91 respondents were selected on consecutive admission; every third respondent who applied for the program was approached. In a clinical detoxification program, 72 respondents who did not continue their treatment with a therapeutic community (TC) (detox only) and 77 who did continue their treatment in a TC were interviewed. All subjects in treatment were interviewed at intake and signed a form of consent. Interviews were conducted by trained staff of the treatment settings. There were regular meetings during which the researcher commented on the interviews. 83 opiate-addicted individuals without treatment were interviewed. They had not received treatment for more than 2 weeks over the past 2 years. They were selected by means of the snowball sampling method with nominee selection (Hendriks, Blanken, \& Adriaans, 1992). In this method, the interviewed respondent names about six other heroin users without treatment contacts. Of these, one is randomly selected and interviewed. All subjects outside of treatment were paid for their participation. The fieldwork was carried out by the researcher and a community fieldworker who was trained in interview techniques. The nonresponse numbers in the different settings were: community: $22 \%$ of the users identified by the chain referral method could not be located or refused to participate and $9 \%$ of the approached users did not show up at the second or third appointment; methadone: $26 \%$ of the approached users refused participation or did not show up; inpatient: $9 \%$ of the respondents left the setting before the required 2 weeks and, therefore, no CIDI interview was recorded. ASI interviews of $11 \%$ of the inpatient heroin users could not be retrieved by the treatment setting. The sociodemographic characteristics of the lost respondents in the treatment settings did not differ from those of the interviewed users.

\section{Procedure}

Two instruments were used. The Dutch version of the Addiction Severity Index $\left(\mathrm{ASI}^{\mathrm{R}}\right.$ ) (Hendriks et al., 1989; McLellan et al., 1980) was used to collect information on several life aspects. These are physical health, employment, alcohol and drug use, legal status, social functioning, and psychiatric problems. Both lifetime and current problems are addressed. For every area an overall "severity rating" was established; this rating was chosen in a range from 0 (no problems/no need for help) to 9 (extreme problems/extreme need for help). Composite scores were also computed, based on recent items of the $\mathrm{ASI}^{\mathrm{R}}$ (Hendriks et al., 1989; McLellan et al., 1985). These composite scores are considered to be more objective than the severity ratings, because the interviewer's opinion does not play a role. The Composite International Diagnostic Interview (CIDI) (Robins et al., 1989) was administered to describe the respondents' psychopathology in terms of $D S M-I I I-R$ disorders. The disorders were grouped into three categories that were previously used by other researchers (Hendriks, 1990; Limbeek et al., 1992; Rounsaville et al., 1982). Recent disorders only (last 6 months) are presented. Major depression, dysthymia, and manic disorder were united in the category "affective disorders." Generalized anxiety, obsessivecompulsive disorder, agoraphobia, and panic disorder together constituted the category "anxiety disorders." So- 
TABLE 1

Percentage of Respondents with 0, 1, 2, and 3 or More Recent Psychiatric Disorders (Measured with CIDI) by ASI Psychiatry Rating

\begin{tabular}{lcccc}
\hline Severity & $\begin{array}{c}0 \\
\text { Disorders } \\
\text { Rating }\end{array}$ & $\begin{array}{c}1 \\
\text { Disorder } \\
(n=85)\end{array}$ & $\begin{array}{c}2 \\
\text { Disorders } \\
(n=52)\end{array}$ & $\begin{array}{c}3 \text { or More } \\
\text { Disorders } \\
(n=77)\end{array}$ \\
\hline$\geq 4$ & $41 \%$ & $53 \%$ & $62 \%$ & $70 \%$ \\
$\geq 5$ & $20 \%$ & $38 \%$ & $44 \%$ & $58 \%$ \\
$\geq 6$ & $1 \%$ & $25 \%$ & $33 \%$ & $45 \%$ \\
\hline
\end{tabular}

cial and simple phobias were left out because too many respondents were classified in the anxiety category due to only one of these, relatively light, phobias. The third category was antisocial personality disorder (ASP). Lifetime schizophrenic disorders make up the fourth category.

\section{Data Analysis}

In general, there are two kinds of overall measures in the ASI: severity ratings and composite scores. When the ASI is used as a screening instrument to identify addicted individuals with psychiatric problems, cut-off points can be used to distinguish between respondents with and without those problems. The choice of such a cut-off point is based more often on intuition than on empirical data. To find out to what extent certain psychiatric disorders were screened, validity measures of sensitivity and specificity of the diagnoses were obtained by comparing the ASI psychiatric overall measures at several cut-off points with the criterion (CIDI). There could be four possible combinations. True-positive (TP) and true-negative (TN) classifications occur when the two types of data agree, false-positive (FP) and false-negative (FN) classifications occur when the two types of data disagree. Sensitivity refers to the percentage of persons with a disease and who are classified by the test as having the problems $(\mathrm{TP} / \mathrm{TP}+\mathrm{FN})$. Specificity points at the percentage of persons without the disease and who were classified by the test as not having the problems (TN/FP + TN) (Bouter \& van Dongen, 1991).

\section{RESULTS}

The results will be presented in four parts. First, it is described to what extent the $\mathrm{ASI}^{\mathrm{R}}$ is capable of screening individuals who have one or more psychiatric disorders. Second, data for categories of psychiatric disorders are presented which concern the different levels of severity ratings of the $\mathrm{ASI}^{\mathrm{R}}$ psychiatry section, and, thirdly, data for comparable categories that concern the different levels of composite scores of the psychiatry section. Finally it is described to what extent the DSM-III-R disorders are screened at $\mathrm{ASI}^{\mathrm{R}}$ item level.

\section{Screening Respondents with One or More Disorders}

Of the 99 respondents with a recent anxiety disorder, affect disorder or schizophrenic disorder, it appeared that $43 \%$ received a severity rating of 6 or higher at the psychiatry section of the $\mathrm{ASI}^{\mathrm{R}}$. For a cut-off point of 5 this was $59 \%$ and for a cut-off point of $4,73 \%$ of these respondents were identified. When ASP disorder is included, the number of respondents with a recent disorder is 169 . At a cut-off point of $6,33 \%$ is screened well. At a cut-off point of $5,50 \%$ was identified, and at a cut-off level of 4 and higher $66 \%$ was identified. Lower cut-off points screen worse. Table 1 shows to what extent respondents with none, one, or more recent psychiatric disorder (excluding ASP disorder) were screened accurately by the psychiatry section of the $\mathrm{ASI}^{\mathrm{R}}$. That the data of this section are not totally compatible with the DSM-III-R data becomes clear from these results. Respondents without a recent psychiatric disorder received severity ratings of 4 or 5 . A cut-off point of 6 was able to distinguish the respondents with a recent disorder from those without. For the respondents with 1, 2, or 3 and more disorders it appeared that a low cut-off point screened reasonable. This improved for respondents with more disorders.

\section{Severity Ratings}

The results in Table 2 represent the relation between the $\mathrm{ASI}^{\mathrm{R}}$ psychiatry ratings and the CIDI diagnoses. The severity ratings were divided into three categories (Low, Mid, and High), previously used by McLellan et al.

TABLE 2

Percentage of Respondents with Pychopathology (Measured with CIDI) by ASI Psychiatry Rating (Low, Mid, High)

\begin{tabular}{lccc}
\hline Recent CIDI Disorders & $\begin{array}{c}\text { ASI-Low } \\
\text { Rating 0-3 } \\
(n=147)\end{array}$ & $\begin{array}{c}\text { ASI-Mid } \\
\text { Rating 4-6 } \\
(n=141)\end{array}$ & $\begin{array}{c}\text { ASI-High } \\
\text { Rating 7-9 } \\
(n=39)\end{array}$ \\
\hline Affective disorder & $9.5 \%$ & $27.0 \%$ & $30.8 \%$ \\
Anxiety disorder & $23.1 \%$ & $27.0 \%$ & $48.7 \%$ \\
Schizophrenic disorders & $1.4 \%$ & $5.7 \%$ & $13.5 \%$ \\
ASP disorder & $26.5 \%$ & $39.7 \%$ & $33.3 \%$ \\
\hline
\end{tabular}


TABLE 3

Affective Disorders, Anxiety Disorders, Schizophrenic Disorders and ASP Disorder (Measured with CIDI) by Several Cut-Off Points on Severity Ratings of the ASI Psychiatry Section $(N=327)$

\begin{tabular}{lccc}
\hline & & & $\begin{array}{c}\text { Correctly } \\
\text { Identified } \\
\text { Cases }\end{array}$ \\
Cut-Off Points & Sensitivity & Specificity & \\
\hline Affective Disorders & & & $49 \%$ \\
Rating $\geq 3$ & 86.2 & 39.7 & $50 \%$ \\
Rating $\geq 4$ & 76.9 & 51.1 & $66 \%$ \\
Rating $\geq 5$ & 60.0 & 67.9 & $66 \%$ \\
Rating $\geq 6$ & 40.0 & 79.4 & \\
Anxiety disorders & & & $44 \%$ \\
Rating $\geq 3$ & 79.2 & 36.9 & $51 \%$ \\
Rating $\geq 4$ & 66.0 & 47.4 & $73 \%$ \\
Rating $\geq 5$ & 58.5 & 66.1 & $38 \%$ \\
Rating $\geq 6$ & 43.4 & 78.8 & $49 \%$ \\
Schizophrenic disorders & & & $64 \%$ \\
Rating $\geq 3$ & 86.6 & 35.2 & $76 \%$ \\
Rating $\geq 4$ & 86.6 & 46.8 & \\
Rating $\geq 5$ & 66.7 & 63.5 & $49 \%$ \\
Rating $\geq 6$ & 60.0 & 73.5 & $53 \%$ \\
ASP disorder & & & $58 \%$ \\
Rating $\geq 3$ & 73.1 & 38.4 & $58 \%$ \\
Rating $\geq 4$ & 63.9 & 38.4 & \\
Rating $\geq 5$ & 46.3 & 76.8 & \\
Rating $\geq 6$ & 26.9 & & \\
\hline
\end{tabular}

(1983) and Hendriks (1990). It was expected that the percentage of respondents with a particular disorder would increase from the low to the middle group and from the middle to the high group. It emerged that this was true with respect to anxiety disorders and schizophrenia, but not with respect to affective disorders and ASP disorders. The number of respondents with an affective disorder in the middle group was $27.0 \%$, which was not very different from the $30.8 \%$ of the high group. For ASP disorders the number of respondents with this disorder was comparable across all three ASI $^{\mathrm{R}}$ categories. This reflects the different character of this Axis II (personality) disorder compared to the other Axis I disorders, which are better reflected in the severity ratings.

Table 3 describes to what extent affective, anxiety, schizophrenic disorders and ASP disorder categories (CIDI) were identified correctly at several cut-off points of the $\mathrm{ASI}^{\mathrm{R}}$ 's psychiatric severity rating. Of the four categories, ASP disorder appeared to be identified worse. At a cut- off score of $5,58 \%$ of the cases were well identified, while the other categories scored about $65 \%$ at this point.

\section{Composite Scores}

In order to describe the relation between the $\mathrm{ASI}^{\circledR} \mathrm{com}$ posite scores and CIDI diagnoses, Table 4 represents percentages of users across the different $\mathrm{ASI}^{\circledR}$ categories with a low, middle, or high composite score. The three categories of composite scores have been formed by calculating the mean $(M=0.24)$, \pm 1 standard deviation $(S D=0.23)$. This procedure was used previously by McLellan et al. (1983) and Stoffelmayer et al. (1989). Because the composite scores range from 0 (no problems) to 1 (severe problems) it was expected that the high category would contain the largest number of respondents with a particular disorder. However, it appeared that the middle group consisted of the largest number of

TABLE 4

Percentage of Respondents with Psychopathology (CIDI) by Category of ASI Composite Score (Low, Mid, High)

\begin{tabular}{|c|c|c|c|}
\hline $\begin{array}{l}\text { Recent CIDI } \\
\text { Disorders }\end{array}$ & $\begin{array}{c}\text { Low Score } \\
0-0.01 \\
(n=111)\end{array}$ & $\begin{array}{l}\text { Mid Score } \\
0.01-0.47 \\
(n=154)\end{array}$ & $\begin{array}{l}\text { High Score } \\
\geq 0.47 \\
(n=59)\end{array}$ \\
\hline Affective disorder & $12.9 \%$ & $50.0 \%$ & $37.1 \%$ \\
\hline Anxiety disorder & $13.5 \%$ & $46.2 \%$ & $40.4 \%$ \\
\hline Schizophrenic disorders & $13.3 \%$ & $66.7 \%$ & $20.0 \%$ \\
\hline ASP disorder & $20.0 \%$ & $62.9 \%$ & $17.5 \%$ \\
\hline
\end{tabular}


respondents who suffered from recent disorders in all four categories. This might be a result of the composite score being based on only the recent items of the $\mathrm{ASI}^{\mathrm{R}}$, whereas the severity rating includes past (lifetime) psychiatric symptoms as well. Indeed, further analyses showed that the lifetime average number of $D S M-I I I-R$ disorders was significantly larger in the high group (2.83) compared to the middle group (2.18) and the low group (1.33) $(p=0.00)$. This indicates that long-term psychiatric information plays an important role in the assessment of the psychiatric severity of psychiatric problems with the $\mathrm{ASI}^{\circledR}$.

Table 5 represents the results of screening CIDI disorders at three cut-off points. When the data were cut off above the mean, respondents with affective disorders were identified best of all $(64.3 \%)$, followed by ASP disorder $(60.1 \%)$, anxiety disorders $(58.1 \%)$, and lifetime schizophrenic disorders $(54.7 \%)$. However, these percentages show that there are no major differences between the various disorders.

Finally, some comparisons were made at item level of the $\mathrm{ASI}^{\mathrm{R}}$. Of the respondents with a lifelong major depression or dysthymia $(N=95), 81.3 \%$ was screened by the $\mathrm{ASI}^{\mathrm{R}}$ question of whether they had ever been depressed, while $47.2 \%$ of respondents without the disorder were correctly classified. Of the respondents with a recent depressive disorder on the CIDI $(N=61), 57.4 \%$ was identified by the $\operatorname{ASI}^{\mathrm{R}}$ question of whether they had been depressed in the past month, whereas $71.6 \%$ without depressive disorders scored negatively at the $\mathrm{ASI}^{\mathrm{R}}$ depression question. Of the lifetime anxiety disorders $(N=181), 65.7 \%$ of respondents were correctly identified by the $\mathrm{ASI}^{\mathrm{R}}$, and $58.1 \%$ of respondents without the disorder were screened correctly. The $\mathrm{ASI}^{\mathrm{R}}$ recognized $46.3 \%$ of respondents with recent anxiety disorders $(N=$
123 ) and $74.3 \%$ of respondents without recent anxiety disorders.

\section{CONCLUSION AND DISCUSSION}

A limitation of this study is that the CIDI diagnoses, which are considered the "golden standard" in this comparison, are also assessments with a better or worse sensitivity and specificity, A comparison with, for instance, clinically assessed disorders might give an indication of the quality of the CIDI results, but even these clinically assessed disorders are not watertight. For example, Kranzler et al. (1995) compared the validity of psychiatric diagnoses that were obtained by a clinical interview (SCID) conducted by a Master's level clinician with the validity of diagnoses that were the result of a nonclinician conducting a standardized interview. They concluded that the psychiatric diagnosis in substance abuse patients may be improved by the addition of elements of structured interviews to the clinician's usual assessment. For the CIDI, several publications showed good validity of almost all diagnoses except for psychotic disorder (Farmer, Katz, McGuffin, \& Bebbington, 1987; Janca, Robins, Cottler, \& Early, 1992; Semler, 1989; Sprengler \& Wittchen, 1989).

Furthermore, the reliability of the results in this study might be limited because data are based on retrospective self-reports of the respondents who were often under the influence of drugs. During the fieldwork, respondents suffering heavy withdrawal symptoms or strong intoxication were not interviewed, but in those cases the appointment was re-arranged for another time. We expect the chances of deliberately falsified answers to be small, because there were no financial or other consequences attached to the answers.

TABLE 5

Affective Disorders, Anxiety Disorders, Schizophrenic Disorders and ASP Disorder by 3 Cut-Off Points on Composite Scores $(N=327)$

\begin{tabular}{lccc}
\hline & & & \\
Cut-off Points & Sensitivity & $\begin{array}{c}\text { Correctly } \\
\text { Identified } \\
\text { Cases }\end{array}$ \\
\hline Affective disorders & & & \\
Low $(\geq 0.01)$ & 87.1 & 39.6 & $48.8 \%$ \\
Mid $(\geq 0.24)$ & 74.2 & 61.9 & $64.3 \%$ \\
High $(\geq 0.47)$ & 38.7 & 86.9 & $77.6 \%$ \\
Anxiety disorders & & & \\
Low $(\geq 0.01)$ & 86.5 & 38.5 & $46.3 \%$ \\
Mid $(\geq 0.24)$ & 59.6 & 57.8 & $58.1 \%$ \\
High $(\geq 0.47)$ & 40.4 & 86.3 & $37.9 \%$ \\
Schizophrenic disorders & & & $54.7 \%$ \\
Low $(\geq 0.01)$ & 86.7 & 35.5 & $79.2 \%$ \\
Mid $(\geq 0.24)$ & 46.7 & 55.0 & \\
High $(\geq 0.47)$ & 20.0 & 82.1 & $55.2 \%$ \\
ASP disorder & & & $60.1 \%$ \\
Low $(\geq 0.01)$ & 80.0 & 42.9 & $61.3 \%$ \\
Mid $(\geq 0.24)$ & 58.1 & 81.9 & \\
High $(\geq 0.47)$ & 18.1 & & \\
\hline
\end{tabular}


The present results indicate that the $\mathrm{ASI}^{\mathrm{R}}$ psychiatry section detects part of the psychopathology cases, but also misses out on a substantial number. For instance, at item level, $18.7 \%$ of respondents with lifetime depression were missed out and $34.3 \%$ of respondents with lifetime anxiety disorders. Also, at the severity rating level, about $35 \%$ of respondents with anxiety, affective, or schizophrenic disorders were missed out at a cut-off level of 5. The detection of ASP disorder was worse. The number of respondents in the group with middle severity ratings (4-6) that reported ASP disorder was larger than in the high group (7-9). At the various cut-off levels the percentage of correctly identified cases with respect to ASP disorder also remained low. This indicates that Axis II personality disorders such as ASP are of a different nature when compared to the Axis I disorders.

One reason for these differences between the instruments is that in a structured psychiatric interview, all $D S M-I I I-R$ symptoms of a disorder are investigated, which results in a categorical diagnoses at disorder level. For each symptom it is checked whether it is severe enough, whether it results from a physical illness or from substance use, whereas the ASI ${ }^{\mathrm{R}}$ psychiatry section measures more at symptom level. It is less extensive and it integrates the information about different types of psychiatric symptoms into a dimensional measure to indicate the severity of the psychiatric problems, regardless of the type of psychopathology. The latter screens only part of the psychopathology cases. Another explanation for the differences that were found between the instruments could be the conclusion of Raskin and Miller (1993) that psychiatric symptoms that are common in active addiction are mainly symptoms that generally disappear within weeks or months of treatment for addiction. Because the CIDI results are described at disorder level, many symptoms might not pass this threshold of the disorder level, while these are screened by the $\mathrm{ASI}^{\mathrm{R}}$. A comparison of the sensitivity and specificity of the ASI ${ }^{\mathrm{R}}$ psychiatry severity rating and the psychiatric composite score shows that the severity rating approaches the recent CIDI diagnoses better than the composite scores. When the scores were compared across three groups (low, mid, high), it turned out that not the highest group but the middle group consisted of the largest number of respondents with psychiatric disorders. This indicates that the inclusion of lifetime items of the $\operatorname{ASI}^{\mathrm{R}}$ psychiatry scale, as is the case with severity ratings, improves comparability with the CIDI results.

What is the best cut-off point to screen a particular type of psychopathology depends on several factors, such as the nature of the disease, the available money, and the consequences for the people undergoing the test-all play a part. For example, a high sensitivity is required with regard to diseases that would deteriorate without treatment, but that can be successfully treated if they are detected in time. A sensitive test is also useful in order to eliminate people without diseases at the start of the diagnostic pro- cess. A negative consequence of choosing a high sensitivity is that persons are sometimes labelled as psychiatric (false positives) without reason. This may lead to emotional damage or medical overconsumption. (Bouter $\&$ van Dongen, 1991). The current study considers mental disorders. The negative effect of severe psychiatric comorbidity on the prognosis for treatment (McLellan et al., 1983; Rounsaville, Dolinsky, Babor, \& Meyer, 1987) underlines the importance of thoroughly screening these disorders. Therefore, a cut-off point with high sensitivity seems most appropriate. Yet another reason for choosing a high sensitivity is that the nature of the psychopathology in opiate-addicted individuals might not be apparent at first sight. When screening takes place at the moment of intake, the chances are that psychological symptoms dissolve during the first weeks of treatment. Therefore, it seems more appropriate to choose for a large number of false positives in order to end up with the true psychiatric disorders.

Implications of the results are that the $\mathrm{ASI}^{\mathrm{R}}$ psychiatry section should only be used very carefully for assessment of psychopathology in opiate-addicted individuals. Because of the low agreement between $\mathrm{ASI}^{\mathrm{R}}$ data and $D S M-I I I-R$ disorders, we advise using the $\mathrm{ASI}^{\mathrm{R}}$ psychiatry section for the first step in a screening process only. The next step would be a clinician's opinion or a more extensive instrument to assess psychopathology. Unfortunately, both take extra time, which might not be available. If this is the case, a relatively low cut-off point, say four, should be used in order not to miss out too many addicted individuals with a disorder. The consequence of this method is that the extra number of false positives that are necessary to find the number of true positives requires additional financial resources. Also, with respect to the rather large number of false positives, especially those in treatment, it is important not to label the client as "psychiatric" based on ASI $^{\mathrm{R}}$ information alone.

\section{REFERENCES}

Abbott, P.J., Weller, S.B., \& Walker, S.R. (1994). Psychiatric disorders of opioid addicts entering treatment: Preliminary data. Journal of Addictive Diseases, 13(3), 1-11.

Beck, A.T., Ward, R.W., Mendelson, M., Mock, J.E., \& Erbaugh, J. (1961). An inventory for measuring depression. Archives of General Psychiatry, 4, 561-571

Bouter, L.M., \& Dongen van, M.C.J.M. (1991). Epidemiologisch onderzoek. Bohn: Stafleu Van Loghum bv, Houten.

Darke, S., Wodak, A., Hall, W., Heather, N., \& Ward, J. (1992). Prevalence and predictors of psychopathology among opoid users. British Journal of Addiction, 87, $771-776$.

Derogatis, L.R. (1983). SCL-90-R: Administration, scoring \& procedures, manual II. Towsen, MD: Clinical Psychometric Research.

Farmer, A.E., Katz, R., McGuffin, P., \& Bebbington, P. (1987). A comparison between the Present State Examination and the Composite International Diagnostic Interview. Archives of Genteral Psychiarry, 44, 1064-1068.

Hendriks, V.H. (1990). Addiction and psychopathology: A multidimensional approach to clinical practice. Dissertation, Erasmus University Rotterdam.

Ilendriks, V.M., Blanken, P., \& Adriaans, N.F.P. (1992). Snowball 
sampling: A pilot study on cocaine use. IVO Series 2. Erasmus University Rotterdam.

Hendriks, V.M., Kaplan, C.D., Limbeek v. J., \& Geerlings, P. (1989). The Addiction Severity Index: Reliability and validity in a Dutch addict population. Journal of Substance Abuse Treatment, 6, 133-141.

Janca, A., Robins, L.N., Cottler, L.B., \& Early, T.S. (1992). Clinical observation of CIDI assessments: An analyses of the CIDI field trials-Wave II at the St. Louis Site. British Journal of Psychiatry, 160, 815-818

Kranzler, H.R., Kadden, R.M., Burleson, J.A., Babor, T.F., Apter, A., \& Rounsaville, B.J. (1995). Validity of psychiatric diagnoses in patients with substance use disorders: Is the interview more important than the interviewer? Comprehensive Psychiatry, 36, 278-288.

Lehman, F.L., Myers, C.P., \& Corty, E. (1989). Assessment and classification of patients with psychiatric and substance abuse syndromes. Hospital and Community Psychiatry, 40, 1019-1025.

Lehman, A.F., Myers, C.P., Dixon, L.B., \& Johnson, J.L. (1994). Defining subgroups of dual diagnosis patients for service planning. Hospital and Community Psychiatry, 45, 556-561.

Lehman, A.F., Myers, P., Thompson, J.W., \& Corty, E. (1993). Implications of mental and substance use disorders, a comparison of singlc and dual diagnosis paticnts. Journal of Nervous and Mental Disease, 181, 365-370.

Limbeek, v. J., Wouters, L., Kaplan, C.D., Geerlings, P.J., \& Alem, v. V. (1992). Prevalence of psychopathology in drug-addicted Dutch. Journal of Substance Abuse Treatment, 9, 43-52.

McLellan, A.T., Luborsky, L., Cacciola, J., Griffith, J., McGrahan, P., \& O'Brien, C.P. (1985). Guide to the Addiction Severity Index: Background, administration and field testing results (National Institute on Drug Abuse. Treatment Research Monograph Series). Washington, DC: U.S. Government Printing Office.

McLellan, A.T., Luborsky, L., Woody, G.E., \& O'Brien, C.P. (1980). An improved diagnostic evaluation instrument for substance abuse patients: the Addiction Severity Index. The Journal of Nervous and Mental Disease, 168, 26-33.

McLellan, A.T., Woody, G.E., Luborsky, L., O'Brien, C.P., \& Druley, K.A. (1983). Predicting response to alcohol and drug abuse treatments: Role of psychiatric severity. Archives of General Psychiatry, 40, 620-625.
Raskin, V.D., \& Miller, N.S. (1993). The epidemiology of the comorbidity of psychiatric and addictive disorders: A critical review. Journal of Addictive Diseases, 12(3), 45-57.

Regier, D.A., Farmer, M.E., Rae, D.S., Locke, B.Z., Keith, S.J., Judd, L.L., \& Goodwin, F.K. (1990). Comorbidity of mental disorders with alcohol and other drug abuse. Journal of the American Medical Association, 264, 2511-2518.

Robins, L.N., Witchen, H-U., Helzer, J.E., Babor, T.F., Burke, J., Farmer, A., Jablensky, A., Pickens, R., Regier, D.A., Sartorius, N., \& Towle, L.H. (1989). The Composite International Diagnostic Interview: An epidemiologic instrument suitable for use in conjunction with different diagnostic systems and in different cultures. Archives of General Psychiatry, 45, 1069-1077.

Rounsaville, B.J., Dolinsky, Z., Babor, T., \& Meyer, R.E. (1987). Psychopathology as a predictor of treatment outcome in alcoholism. Archives of General Psychiatry, 44, 505-513.

Rounsaville, B.J., Kosten, T.R., Weissman, M.W., \& Kleber, H.D. (1986). Prognostic significance of psychopathology in untreated opiate addicts. Archives of General Psychiatry, 43, 739-745.

Rounsaville, B.J., Weissman, M.M., Kleber, H., \& Wilber, C. (1982). Heterogeneity of psychiatric diagnosis in treated opiate addicts. Archives of General Psychiatry, 39, 161-166.

Semler, G. (Ed). (1989). Reliabilitat und validitat des Composite International Diagnostic Interview: Inaugural-dissertation zur erlangung des akademischen grades eines doktors der philosophie. Mannheim, Germany: Universitat Mannheim.

Sprengler, P., \& Wittchen, H-U. (1989). Procedural validity of standardized symptom questions for the assessment of psychotic symptoms: a comparison of the CIDI with two clinical methods. Comprehensive Psychiatry, 29, 309-322.

Stoffelmayer, B.E., Benishek, L.A., Humphreys, K., Lee, J.A., \& Mavis, B.E. (1989). Substance abuse prognosis with an additional psychiatric diagnosis: Understanding the relationship. Journal of Psychoactive Drugs, 21, 145-152.

Swift, W., Williams, G., Neill, O., \& Grenyer, B. (1990). The prevalence of minor psychopathology in opioid users seeking treatment. British Journal of Addiction, 85, 629-634.

Turnbull, J.M., \& Roszell, D.K. (1993). Dual diagnosis. Primary Care, 20, $181-190$. 